\title{
A dark past, a restrained present, and an apocalyptic future: Time perspective, personality, and life satisfaction among anorexia nervosa patients
}

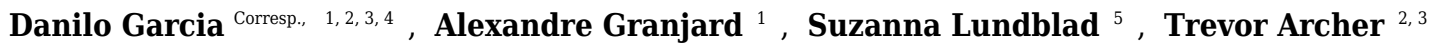 \\ 1 Blekinge Centre of Competence, Blekinge County Council, Karlskrona, Sweden \\ 2 Department of Psychology, University of Gothenburg, Gothenburg, Sweden \\ 3 Network for Empowerment and Well-Being, Sweden \\ 4 Department of Psychology, Lund University, Lund, Sweden \\ 5 Psychiatry Affective, Anorexia \& Bulimia Clinic for Adults, Sahlgrenska University Hospital, Gothenburg, Sweden \\ Corresponding Author: Danilo Garcia \\ Email address: danilo.garcia@icloud.com
}

Background: Despite reporting low levels of well-being, anorexia nervosa patients express temperament traits (e.g., extraversion and persistence) necessary for high levels of life satisfaction. Nevertheless, among individuals without eating disorders, a balanced organization of the flow of time, influences life satisfaction beyond temperamental dispositions. A balanced time perspective is defined as: high past positive, low past negative, high present hedonistic, low present fatalistic, and high future. We investigated differences in time perspective dimensions, personality traits, and life satisfaction between anorexia nervosa patients and matched controls. We also investigated if the personality traits and the outlook on time associated to positive levels of life satisfaction among controls, also predicted anorexia patients' life satisfaction. Additionally, we investigated if time perspective dimensions predicted life satisfaction beyond personality traits among both patients and controls.

Method: 88 anorexia nervosa patients from a clinic in the West of Sweden and 111 gender-age matched controls from a university in the West of Sweden participated in the Study. All participants responded to the Zimbardo Time Perspective Inventory, the Ten Item Personality Inventory, and the Temporal Satisfaction with Life Scale.

Results: A t-test showed that patients scored higher in the past negative, the present fatalistic, and the future dimensions, lower in the past positive and the present hedonistic dimensions, higher in conscientiousness, extraversion, and agreeableness, and lower in life satisfaction. Regression analyses showed that life satisfaction was predicted by openness to experience and emotional stability for controls and by emotional stability among patients. When time dimensions were entered in the regression, emotional stability and the past negative and past positive time dimensions predicted life satisfaction among controls, but only the past positive and present hedonistic time dimensions predicted life satisfaction among patients.

Conclusion: Anorexia patients were less satisfied with life despite being more conscientious, social, and agreeable than controls. Moreover, compared to controls, patients had an unbalanced time perspective: a dark view of the past (i.e., high past negative), a restrained present (i.e., low present hedonistic) and an apocalyptic view of the future (i.e., high present fatalistic). It is plausible to suggest that, therapeutic interventions should focus on empowering patients to cultivate a sentimental and positive view of the past (i.e., high past positive) and the desire to experience pleasure without concern for future 
consequences (i.e., high present hedonistic) so that they can make self-directed and flexible choices for their own well-being. Such interventions might have effects on life satisfaction beyond the patients' temperamental disposition. 
1 Under editorial evaluation in PeerJ

2 Please do not quote without permission

3

4

5

6

7

8

9

\section{A Dark Past, a Restrained Present, and an Apocalyptic Future:}

Time Perspective, Personality, and Life Satisfaction among Anorexia Nervosa Patients Danilo Garcia'1,2,3,4*, Alexandre Granjard ${ }^{1}$, Suzanna Lundblad ${ }^{2,5}$, Trevor Archer ${ }^{2,3}$ ${ }^{1}$ Blekinge Centre of Competence, Blekinge County Council, Karlskrona, Sweden ${ }^{2}$ Department of Psychology, University of Gothenburg, Gothenburg, Sweden ${ }^{3}$ Network for Empowerment and Well-Being, Sweden ${ }^{4}$ Department of Psychology, Lund University, Lund, Sweden

${ }^{5}$ Sahlgrenska University Hospital, Psychiatry Affective, Anorexia \& Bulimia Clinic for Adults, 
Abstract

Background: Despite reporting low levels of well-being, anorexia nervosa patients express temperament traits (e.g., extraversion and persistence) necessary for high levels of life satisfaction. Nevertheless, among individuals without eating disorders, a balanced organization of the flow of time, influences life satisfaction beyond temperamental dispositions. A balanced time perspective is defined as: high past positive, low past negative, high present hedonistic, low present fatalistic, and high future. We investigated differences in time perspective dimensions, personality traits, and life satisfaction between anorexia nervosa patients and matched controls. We also investigated if the personality traits and the outlook on time associated to positive levels of life satisfaction among controls, also predicted anorexia patients' life satisfaction. Additionally, we investigated if time perspective dimensions predicted life satisfaction beyond personality traits among both patients and controls.

Method: 88 anorexia nervosa patients from a clinic in the West of Sweden and 111 gender-age matched controls from a university in the West of Sweden participated in the Study. All participants responded to the Zimbardo Time Perspective Inventory, the Ten Item Personality Inventory, and the Temporal Satisfaction with Life Scale.

Results: A t-test showed that patients scored higher in the past negative, the present fatalistic, and the future dimensions, lower in the past positive and the present hedonistic dimensions, higher in conscientiousness, extraversion, and agreeableness, and lower in life satisfaction. Regression analyses showed that life satisfaction was predicted by openness to experience and emotional stability for controls and by emotional stability among patients. When time dimensions were entered in the regression, emotional stability and the past negative and past positive time dimensions predicted life satisfaction among controls, but only the past positive and present hedonistic time dimensions predicted life satisfaction among patients.

Conclusion: Anorexia patients were less satisfied with life despite being more conscientious, social, and agreeable than controls. Moreover, compared to controls, patients had an unbalanced time perspective: a dark view of the past (i.e., high past negative), a restrained present (i.e., low present hedonistic) and an apocalyptic view of the future (i.e., high present fatalistic). It is plausible to suggest that, therapeutic interventions should focus on empowering patients to cultivate a sentimental and positive view of the past (i.e., high past positive) and the desire to experience pleasure without concern for future consequences (i.e., high present hedonistic) so that they can make self-directed and flexible choices for their own well-being. Such interventions might have effects on life satisfaction beyond the patients' temperamental disposition. 
63

64

65

66

67

68

69

70

\section{Introduction}

"[...] and in addition to the feeling of being full there was another more terrifying one, as if a hundred appetites were raging out of control within her. She couldn't explain it, but she felt as if everything was in chaos and something awful was going to happen. She had eaten and now something terrible would occur."

In The Best Little Girl in the World by Steven Levenkron,

Eating disorders present a serious and potentially life-threatening condition. This is especially true for anorexia nervosa, which is characterized by episodes of self-starvation, the preference for being underweight, a distorted body image, and an intense fear of gaining weight (Lee, Cloninger \& Chae, 2015). This line of research shows that diet and eating behaviors are strongly associated with particular personality characteristics in clinical samples (e.g., Lee, Cloninger \& Chae, 2015; Anckarsäter, Hofvander, Billstedt, Gillberg, Gillberg, Wentz \& Råstam, 2012), making personality a major factor of eating disorders in general (Lilenfeld, Wonderlich, Riso, Crosby \& Mitchell, 2006; Cassin \& von Ranson, 2005). Eating disorder patients describe themselves as anxiety prone, with low self-esteem, and poor emotional selfregulation. Besides these self-descriptions, anorexia nervosa patients also describe themselves as rigid, industrious/persistent, and perfectionists (e.g., Akan \& Grilo, 1995). These personality profile and their propensity to experience anxiety and negative affect (Harney, FitzsimmonsKraft, Maldonado \& Bardone-Cone, 2014; Spring \& Bulik, 2014; Lundblad, Garcia, Hansson \& Archer, 2015; Lundblad, Magnusson, Hansson \& Archer, 2015) might lead to cognitiveemotional dysfunctions, such as, intolerance of uncertainty (cf. Sternheim Startup \& Sschmidt, 2011; Sternheim, Konstantellou, Startup \& Schmidt, 2011; Sternheim, Startup \& Schmidt, 2015). 
88 This behavior is almost synonymous with neuroticism, but at the same time these patients

89 present a picture of the self as conscientious and persistent. Paradoxically, conscientiousness and

90 persistence have been linked to well-being and happiness (Garcia, 2011a; Garcia, 2012; Garcia,

91 Ghiabi, Moradi, Siddiqui \& Archer, 2013), but eating disorder patients, especially anorexia

92 nervosa patients, express an absence of positive emotions and lack of satisfaction in several

93 planes of their lives (Kitsantas, Gilligan \& Kamata, 2003; Phillipou, Abel, Castle, Hughes,

94 Gurvich, Nibbs \& Rosell, 2015; Dapelo, Bodas, Morris \& Tchanturia, 2016; Brand-Gothelf,

95 Leor, Apter \& Fennig, 2014; Lavender, Mason, Utzinger, Wonderlich, Crosby, Engel, Mitchell,

96 Le Grange, Crow \& Peterson, 2016; Tomba, Offidani, Tecuta, Schumann \& Ballardini, 2014).

97 Thus, the question is if, as it is among individuals without eating disorders, these personality

98 traits are predictors of life satisfaction among anorexia nervosa patients or if there are other

99 aspects of the being that are associated with life satisfaction across healthy and unhealthy 100 individuals.

101 In this context, the Science of Well-being suggests that individual differences in 102 personality, influence the physical, psychological, and social aspects of health and well-being of 103 all individuals (Cloninger, 2004; Garcia \& Rosenberg, 2016). Nevertheless, instead of linking specific temperament traits, such as extraversion and neuroticism, to well-being, Cloninger's Science of Well-Being focuses on self-awareness of the unity of being through sustainable personality development in three dimensions (Cloninger, 2004, 2006, 2007, 2013; Garcia \&

107 Rosenberg, 2016). In Cloninger's paradigm, unity of being represents a complete, coherent and 108 harmonious sense of the self, giving raise to feelings of hope in one self's ability to cope and make decisions (i.e., Self-directedness), feelings of love and empathy towards others (i.e.,

110 Cooperativeness), and feelings of faith in that we are part of something beyond the self and 
111 others (i.e., Self-transcendence). In short, the ability to be self-aware and organize one's life in a

112 coherent manner is more important to well-being than specific temperament traits, such as, 113 extraversion and persistence.

114 Indeed, in line with their personality characteristics (i.e., high levels of neuroticism and 115 persistence), anorexia nervosa patients display an inability or difficulty to evaluate the future 116 long-term outcomes of their actions/choices and also an incapacity or inflexibility to adapt their 117 mindset/strategies to new information or novel environmental stimuli (Tenconi, Degortes, 118 Clementi, Collantoni, Pinato, Forzan, Cassina, Santonastaso \& Favaro, 2016). Thus, perhaps 119 explaining their intolerance of uncertainty (cf. Sternheim, Konstantellou, Startup \& Schmidt, 120 2011; Sternheim, Startup \& Schmidt, 2011). The cognitive ability to organize the past, present, 121 and future (i.e., a person's time perspective) in a coherent manner is indeed an important aspect 122 of an individual who can make self-directed choices for her/his own well-being and flexible 123 adapt to new situations (Cloninger, 2004; Garcia, Sailer, Nima \& Archer, 2016). As a matter of 124 fact, a balanced organization of the flow of time seems to influence life satisfaction beyond temperament traits (Zhang \& Howell, 2011).

A balanced or coherent time perspective may be described as: a sentimental and positive view of the past (i.e., high past positive), a less pessimistic attitude toward the past (i.e., low past negative), the desire to experience pleasure without concern for future consequences (i.e., high present hedonistic), a less fatalistic and hopeless view of the future (i.e., low present fatalistic), and the ability to find reward in achieving specific long-term goals (i.e., high future) (Zimbardo

131 \& Boyd, 1999; Zimbardo, Keough \& Boyd, 1997). Individuals’ perspective of time predicts the

132 reported use of alcohol, drug, and tobacco (Keough, Zimbardo \& Boyd, 1999), risky driving 133 (Zimbardo, Keough \& Boyd, 1997; Boyd \& Zimbardo, 2005), indecision and avoidant 
134 procrastinations (Díaz-Morales, Ferrari \& Cohen, 2008), environmental engagement (Milfont,

135 Wilson \& Diniz, 2012), the choice of food and of partner, educational achievement, and the

136 distinctness of future goals (Zimbardo \& Boyd, 1999). Time perspective is also related to well-

137 being - negative views of the past have been reported to be associated with depression, whereas

138 positive views of the past have been reported to be associated with happiness and life satisfaction

139 (Bruehlman-Senecal \& Ayduk, 2015; Zimbardo \& Boyd, 1999; see also Stolarski Matthews,

140 Postek, Zimbardo \& Bitner, 2013; Sailer, Rosenberg, Nima, Gamble, Gärling, Archer \& Garcia,

141 2014; Garcia, Sailer, Nima \& Archer, 2016). In relation to anorexia patients, however, if positive

142 information of the present, or past for that matter (e.g., they have become thinner), is not well

143 adjusted into their mindset (e.g., "I'm still overweight"), then even if long-term goals are future

144 oriented, these goals might not be healthy in nature (e.g., "I need to eat less").

145 The present study

146 To the best of our knowledge no other study has examined if anorexia nervosa patients actually

147 differ in their outlook of time from controls. Interesting, the few studies on eating disorders

148 suggest that individuals who are preoccupied with immediate concerns and pleasures and who

149 are unable to comprehend how their current actions will affect them in the future (i.e., high in the

150 present hedonistic and low in the future time perspectives) may be more likely to place

151 themselves at risk for binge eating and binge drinking (Boyd \& Zimbardo, 2005). Probably due

152 to the considerable direct positive outcomes (i.e., pleasure and disinhibition) linked to binge

153 behaviors (Laghi, Liga, Baumgartner \& Baiocco, 2012). Additionally, individuals who engage in

154 binge behaviors also present an outlook oriented towards a fatalistic present, which might cloud

155 the sense of control they have over their actions and also influence them to lack hope for the

156 future (Laghi, Liga, Baumgartner \& Baiocco, 2012). It is plausible that anorexia nervosa 
157 patients also have this specific outlook on time, along a time perspective associated with low life 158 satisfaction and psychological distress (i.e., high past negative, low past positive, high present 159 fatalistic) (cf. Culbert, Lavender, Crosby, Woderlich, Engel, Peterson, Mitchell, Crow, Le 160 Grange, Cao \& Fischer, 2016; Seidel, Petermann, Diestel, Ritschel, Boehm, King, Geisler, 161 Bernardoni, Roessner, Goschke \& Ehrlich, 2016). After all, anorexia nervosa patients share other 162 forms of risky behaviours, low levels of life satisfaction, depression, and anxiety with patients 163 with eating disorders in general. However, we expected that anorexia nervosa patients in 164 comparison to controls would delay gratification by restraining themselves from engaging in 165 pleasant behaviors in the present and to focus on negative consequences of their current actions 166 (i.e., less present hedonistic), and also by visualizing and formulating future goal states that 167 shape their current judgments and decisions (i.e., high future oriented). That is, anorexia patients are expected to express high levels of future time perspective and conscientiousness (i.e., industrious and perfectionists), but at the same time they are also expected to express high levels of neuroticism and an incoherent time perspective (i.e., high past negative, low past positive, high present fatalistic) and low life satisfaction.

In addition to differences in personality, time perspective, and life satisfaction between anorexia nervosa patients and controls, we also investigated the effect of personality and outlook on time on individuals' level of life satisfaction. Specifically, we investigated if the personality traits and the outlook on time associated to positive levels of life satisfaction among controls, 176 also predicted anorexia patients' life satisfaction. Additionally, we investigated if time 177 perspective dimensions predicted life satisfaction beyond personality traits. We found this important in order to shade light on other aspects of the being, in this case the ability to organize

179 the flow of time, that might influence well-being beyond temperament traits. If it is so, this will 
180 give suggestions for the development or use of interventions that target well-being rather than ill181 being or symptoms. After all, the absence of life satisfaction and positive emotions is a serious 182 problem because it is more predictive of subsequent mortality and morbidity than the presence of 183 negative emotions (Huppert \& Whittington, 2003). For instance, although some reviews of meta184 analyses show that cognitive behavioral therapy is effective for different disorders (e.g., unipolar depression, generalized anxiety disorder, panic disorder with or without agoraphobia, social phobia, posttraumatic stress disorder, and childhood depressive and anxiety disorders) (Butler,

187 Chapman, Forman \& Beck, 2006), single studies and other meta-analyses show either only moderate positive effects on mental health (e.g., Wang, Simon, Avorn, Azocar, Ludman, McCulloch, Petukhova \& Kessler, 2007) or mixed results (Hofmann, Asnaani, Vonk, Sawyer \& 190 Fang, 2012; Moore, Kapur, Hawton, Richards, Metcalfe \& Gunnell, 2016). Moreover, specific reviews of the anorexia nervosa literature suggest that no single psychological intervention has clear superiority in treating these patients, thus, highlighting the importance of the development of novel interventions (Bodell \& Keel, 2010). In this context, therapeutic interventions targeting the development of life satisfaction, sense of autonomy and control, goal-directed behavior, selfempowerment, cooperativeness, empathy, and sense of commitment and belonging to society (i.e., well-being therapy or person-centered well-being coaching) have been shown to provide 197 alleviation for mental health problems and disabilities, such as affective and behavioral 198 disorders, in general and clinical populations (Cloninger, 2004, 2006; Fava, Ruini, Rafanelli, 199 Finos, Salmaso, MAngelli \& Sirigatti, 2005; Fava, Rafanelli, Cazzarro, Conti \& Grandi, 1998; Fava \& Ruini, 2003; Fava \& Tomba, 2009; Ruini, Belaise, Brombin, Caffo, Fava, 2006; Ruini, Masoni, Ottolini, Ferrari, 2014; Ruini, Albieri \& Vescovelli, 2014; Ruini, Vescovelli, Carpi \& Masoni, 2017). Randomized controlled trials of well-being therapy, in patients with mental 
203 disorders, show improvements, such as, treatment adherence, less relapse and recurrence rates

204 when compared with cognitive behavioral therapy or psychotropic medications alone (Cloninger, 205 2006).

\section{Methods}

207

208

209

210

211

212

213

214

215

216

217

218

219

220

221

222

223

224

\section{Ethical statement}

The data at the clinic was collected as part of the development of technics and also as a follow up of the therapies conducted at the clinic. After consultation with the central ethical review board we arrived at the conclusion that the design of the study (e.g., all participants' data were anonymous to the researchers and will not be used for commercial or other non-scientific purposes) required only informed consent from the participants.

\section{Participants and procedure}

Patients ( $N=88$ females, age range between 24 to 45 years) presenting either restrictive anorexia nervosa or anorexia nervosa with both starving combined with binge eating and purging participated in the study. All anorexia patients had a history of unsuccessful interventions and were referred from the Department of General Psychiatry, Sahlgrenska University Hospital (Gothenburg, Sweden). The healthy volunteers (i.e., 114 Controls matched by age, gender, education, socioeconomic status) were university students selected from a larger sample collected for another study (Sailer, Rosenberg, Nima, Gamble, Gärling, Archer \& Garcia, 2014). The patient group had all been afflicted with the eating disorder symptoms for over five years on arrival at the Anorexia and Bulimia Clinic for adults (Sahlgrenska University Hospital). To the best of our knowledge, the patients did not suffer from severe malnutrition when they participated the study. 
All the patients who were contacted agreed to participate. On arrival at the clinic, each

226

227

228

229

230

231

232

233

234

235

236

237

238

239

240

241

242

243

244

245

246

247

patient was met by the respective professional workers, nurse, psychologist, or physician and then completed the Eating Disorder Inventory-2 to measure symptoms of eating disorder and was given their diagnosis by the staff. Thereafter, patients received instructions and were allowed 3045 min to respond to the battery of instruments. The university students in the control group were asked to participate during class hours and were allowed the same amount of time for completing the survey.

\section{Measures}

\section{Time perspective}

The Zimbardo Time Perspective Inventory (Zimbardo \& Boyd, 1999) consists of 56 items that measure the following five time dimensions: Past Positive (e.g., "It gives me pleasure to think about my past'), Past Negative (e.g., "I think about the good things that I have missed out on in my life'”), Present Hedonistic (e.g., “Taking risks keeps my life from becoming boring'), Present Fatalistic (e.g., "Fate determines much in my life'), and Future (e.g., "I believe that a person's day should be planned ahead each morning'). The Swedish version has been used in previous studies and showed good psychometric properties (e.g., Sailer, Rosenberg, Nima, Gamble, Gärling, Archer \& Garcia, 2014; Garcia, Sailer, Nima \& Archer, 2016; Garcia, Nima \& Lindskär, 2016) and its psychometric properties have been validated in many different languages (Milfont, Wilson \& Diniz, 2008; Liniauskaite \& Kairys, 2009; Díaz-Morales, 2006).

\section{Personality}

The Ten Item Personality Inventory (Gosling, Rentfrow \& Swan 2003) is a short ten-item measure that asks to which extent $(1=$ not at all; $5=$ very much $)$ the participant sees herself/himself as open to experience, conscientious, extrovert, agreeable, and neurotic. The 
248 inventory measures each Big Five trait through two items for each trait (e.g., I see myself as

249 "extraverted, enthusiastic" and "quite, reserved" as measures of extraversion).

250 Temporal life satisfaction

251 The Temporal Satisfaction With Life Scale (Pavot, Diener \& Suh, 1998) comprises 15-items

252 rated on a 7-point Likert scale ( $1=$ strongly disagree, 7 = strongly agree) assessing past (e.g., " If

253 I had my past to live over, I would change nothing'”), present (e.g., "I would change nothing

254 about my current life'), and future life satisfaction (e.g., "There will be nothing that I will want

255 to change about my future'). The Swedish version of the instrument has been used in previous

256 studies (Garcia, 2011b; Sailer, Rosenberg, Nima, Gamble, Gärling, Archer \& Garcia, 2014;

257 Garcia, Rosenberg \& Siddiqui, 2011; Garcia, Nima \& Lindskär, 2016).

\section{Statistical methods}

259 We conducted a t-test for independent samples in order to test differences perspective 260 dimensions, personality, and life satisfaction between anorexia nervosa patients and matched 261 controls. Two separated regression analyses (i.e., one for the patient sample and one for the 262 control sample) were conducted to investigate if the personality traits and the outlook on time 263 associated to positive levels of life satisfaction among controls, also predicted anorexia patients' 264 life satisfaction. In both regressions, personality and time perspective dimensions were the 265 predictors and life satisfaction the outcome. Additionally, these regressions aimed to investigated 266 if time perspective dimensions predicted life satisfaction beyond personality traits, thus, 267 personality was the predictor in the first model and both personality and time perspective 268 dimensions the predictors in the second model. 
270 We first conducted a t-test to compare if anorexia patients differed in the five time perspective

271 dimensions, the Big Five traits, and temporal life satisfaction. In short, anorexia patients scored

272 higher in the past negative, the present fatalistic, and the future dimensions and higher in

273 conscientiousness, extraversion, and agreeableness. Controls scored higher in both the past

274 positive and the present hedonistic dimensions and also higher in temporal satisfaction with life

275 (see Table 1).

276

277

278

279

280

281

282

283

284

285

286

287

288

289

290

291

Table 1 should be here

Next, we conducted multiple regression analyses in which temporal satisfaction with life was the outcome variable and personality was the predictor in the first model and time perspective the predictor in the second model. These analyses were conducted separately for each participant group in order to investigate if the personality traits and the outlook on time associated to positive levels of life satisfaction among controls, also predicted anorexia patients' life satisfaction. Additionally, these regressions aimed to investigated if time perspective dimensions predicted life satisfaction beyond personality traits.

For anorexia patients, the multiple regression revealed that at step one, personality contributed significantly to the regression model $(F(5,68)=3.69, p<.01)$ and accounted for $23 \%$ of the variation in temporal satisfaction with life. In this first step, emotional stability (positively) was the only significant predictor of temporal satisfaction with life among anorexia patients (see Table 2). Introducing the time perspective dimensions explained an additional 23\% of variation in temporal satisfaction with life. This change in $R^{2}$ was significant $(F(10,68)=$ $4.82, p<.001)$. In this second step, emotional stability was no longer a significant predictor of temporal satisfaction with life. Instead, both the past positive (positively) and the present 
292 hedonistic (positively) time perspective dimensions predicted significantly temporal satisfaction

293 with life among anorexia patients (see Table 2).

294 For participants in the control group, the multiple regression revealed that at step one,

295 personality contributed significantly to the regression model $(F(5,98)=5.12, p<.001)$ and

296 accounted for $21 \%$ of the variation in temporal satisfaction with life. In this first step, openness

297 to experience (negatively) and emotional stability (positively) were the significant predictors of 298 temporal satisfaction with life among controls (see Table 2). Introducing the time perspective 299 dimensions explained an additional 46\% of variation in temporal satisfaction with life. This 300 change in $R^{2}$ was significant $(F(10,93)=18.47, p<.001)$. In this second step, emotional 301 stability (positively) and both the past negative (negatively) and past positive (positively) time 302 perspective dimensions predicted significantly temporal satisfaction with life among controls 303 (see Table 2).

Table 2 should be here

\section{Discussion}

306

307

308

309

310

311

312

313

314

We investigated differences in time perspective dimensions, personality traits, and life satisfaction between anorexia nervosa patients and matched controls. We also investigated if the personality traits and the outlook on time associated to positive levels of life satisfaction among controls, also predicted anorexia patients' life satisfaction. Additionally, we investigated if time perspective dimensions predicted life satisfaction beyond personality traits among both patients and controls. Our results showed that anorexia patients had a darker and less sentimental view of the past (i.e., high past negative and low past positive), a higher reluctance to experience pleasure (i.e., low present hedonistic), a more fatalistic and hopeless view of the future (i.e., high present fatalistic), and at the same time a higher tendency to find reward in achieving specific 
315 long-term goals (i.e., high future). Moreover, the patients were higher in conscientiousness,

316 extraversion, agreeableness, and lower in life satisfaction. In other words, patients' time-

317 awareness is placed in a dark past, an extremely restrained present, and an apocalyptic future,

318 while their self-awareness is focused on them as hard-workers (i.e., conscientiousness), external

319 positive stimuli (i.e., extroversion), and pleasing and being kind to other people (i.e.,

320 agreeableness). In other words, presenting a personality usually associated with happiness and

321 well-being, but an unbalanced time perspective or an unhappy outlook on time. In essence, the

322 personality traits measured here seem to be necessary for high levels of life satisfaction but not

323 sufficient (cf. Cloninger, 2004). Instead, individuals level of self-awareness is probably what

324 helps individuals to adapt to internal and external conditions (Cloninger, 2004; Ruini, 2017).

325 This picture of the self in time (i.e., time perspective) and space (i.e., personality) that the

326 patients present goes in line with earlier studies in which anorexia patients describe themselves

327 as rigid, industrious, and perfectionists (e.g., Akan \& Grilo, 1995). In the present study, however,

328 our results also suggest that these time-space characteristics might lead to cognitive-emotional-

329 social dysfunctions in anorexia nervosa patients (cf. Sternheim, Konstantellou, Startup \&

330 Schmidt, 2011; Sternheim, Startup \& Schmidt, 2011; Cardi, Esposito, Bird, Rhind, Yiend,

331 Schifano, Hirsch \& Treadure, 2015). For instance, a focus of the self in relation to external

332 positive stimuli (i.e., high extraversion) in conjunction with a extremely restrictive present (i.e.,

333 low present hedonistic) for future reward (i.e., high future) might lead to a persistent attitude

334 towards self-starving in an already highly conscientious individual with an apocalyptic view of

335 the future (i.e., high present fatalistic). This description suggests a persistent striving for future

336 reward from and individual without hope for the future which might explain why anorexia

337 nervosa patients display an inability or difficulty to evaluate the future long-term outcomes of 
338 their actions/choices and also an incapacity or inflexibility to adapt their mindset/strategies to

339 new information or novel environmental stimuli (cf. Tenconi, Degortes, Clementi, Collantoni,

340 Pinato, Forzan, Cassina, Santonastaso \& Favaro, 2016).

341 Unsurprisingly, for patients, a better view of the past and a more hedonistic present (i.e., a

342 less restrictive attitude towards the present) seems to increase their life satisfaction. When it

343 comes to the controls, the past positive dimension and the past negative dimensions together with

344 emotional stability were the main predictors. Suggesting that the cultivation of a sentimental and

345 positive view of the past (i.e., high past positive) would lead to increases in life satisfaction for

346 both patients and individuals without eating disorders, but that increases in the desire to

347 experience pleasure without concern for future consequences (i.e., high present hedonistic)

348 would lead to increases in life satisfaction only among anorexia nervosa patients. Moreover,

349 personality did not seem to play the same kind of role for patients as for controls. This is against

350 most studies on life satisfaction, which show that emotional stability or low neuroticism, along

351 extraversion, is one of the major predictors of life satisfaction (Pavot, Diener \& Suh, 1998).

352 Again, temperament traits might help to define the type of disorder, but not if a person would

353 develop a disorder (Cloninger, 2004). In this study, not only did patients present what the

354 literature would partially define as a happy personality, but also these traits were not even

355 associated with patients' life satisfaction when time perspective was introduced as a predictor.

356 Hence, we argue that temperament traits do not define who the happy people are and that

357 focusing on the cultivation of specific time dimension would lead to higher well-being among

358 patients. This effect seems to go beyond the patients' temperamental dispositions. That being

359 said, although we stated that emotionally stability played a role for controls' life satisfaction but 
360 not for patients, we cannot rule out that this difference was rather because the relationship

361 between personality traits-life satisfaction was less strong for patients to begin with.

\section{Limitations and suggestions for future studies}

363 One limitation in the present study was that we used a very short instrument to measure

364 personality. Also in this line, although the big five is the most well-established model of 365 personality in psychology, in psychiatry, Cloninger's biopsychosocial model (Cloninger, 2004)

366 presents another way to think about personality. This model, does not only cover temperament or

367 people's emotional reactions, but also their character or goals and values as a ternary structure of

368 human self-awareness: self-directedness or the person's relation to herself, cooperativeness or

369 the person's relation to others, and self-transcendence or the person's relation the world and

370 universe as a whole. In other words, Cloninger's biopsychosocial model of personality present a

371 system of descriptions of both pathological functioning, normal functioning and optimal

372 functioning (Ruini, 2017). This personality model is a non-linear model that seems to capture the

373 complex dynamics of personality and well-being because it takes into account the interaction

374 within temperament traits and character traits and also the person's temperament and character

375 profiles, that is, within and between automatic emotional reactions and systems of self-regulation

376 (Cloninger \& Garcia, 2005; Garcia, Lester, Cloninger \& Cloninger, 2017ab; Garcia, Cloninger,

377 Lester \& Cloninger, 2017). By seeing personality as holographic and ternary in nature,

378 Cloninger's model may allow a better understanding of how self-awareness in time (i.e., past,

379 present, and future) and space (i.e., self, others, and the world as a whole) influences anorexia 380 patients' satisfaction with life.

In addition, although matching the participants is a recommendable technique to

382 compare, in this case, time perspective, personality and life satisfaction among patients and non- 
383 patients, it is important to point out the risk of overmatching. According to the literature, age and

384 gender used here as confounders, are associated with the prevalence of anorexia nervosa

385 (Lundblad, Hansson \& Archer, 2014; Lundblad, Garcia, Hansson \& Archer, 2015; Lundblad,

386 Magnusson, Hansson \& Archer, 2015), which might cause statistical bias (Rubin, 1973;

387 Anderson, Kish \& Cornell, 1980). Importantly, although we matched for age, the choice of

388 university students as matched controls can be challenged on whether they are representative for

389 the population from which the patients derived. Future studies should therefore use other

390 variables, such as socioeconomic status, as confounders and use other populations as controls.

\section{Conclusion and final remarks}

392 Anorexia patients were less satisfied with life despite being more conscientious, extrovert, and

393 agreeable than controls. Paradoxically, these personality traits are often addressed as important

394 for a happy life. Nevertheless, patients had an unbalanced time perspective: a dark view of the

395 past (i.e., high past negative), a restrained present (i.e., low present hedonistic) and an

396 apocalyptic view of the future (i.e., high present fatalistic). The patient group's dark attitude

397 towards their history is well in line with experiences in clinical settings. Many of the patients

398 have traumatic experiences from the past and fatalistic views of both the present and the future.

399 Additionally, the patients' view of themselves as kind and pleasant might be demanding and

400 make life difficult for someone with a dark apprehension of the past and the future: "people are

401 kind and I'm agreeable but there is no hope for the future, hence no meaning". It is plausible to

402 suggest that, therapeutic interventions should focus on empowering patients to feel safe to

403 explore the inherently unpredictable world and on becoming more flexible or resilient (Harrison,

404 Fisher, Watling \& Sternheim, 2016). Additionally, encouraging patients to cultivate a

405 sentimental and positive view of the past (i.e., high past positive) and the desire to experience 
406 pleasure without concern for future consequences (i.e., high present hedonistic). For instance,

407 interventions targeting the development of life satisfaction and character have been shown to 408 provide alleviation for mental health problems and disabilities, such as affective and behavioral 409 disorders, in general and clinical populations (e.g., Cloninger, 2004, 2006; Fava, Ruini, 410 Rafanelli, Finos, Salmaso, MAngelli \& Sirigatti, 2005; Ruini, 2017; Garcia, Drugge, Blixt 411 Samuelsson, Storm, Archer \& Cloninger, 2016).

412

413

414

415

416

417

418

419

420

421

422

423

424

425

426

427

\section{References}

Akan GE, Grilo CM. Sociocultural influences on eating attitudes and behaviors, body image, and psychological functioning: a comparison of African-American, Asian-American, and Caucasian college women. Int J Eat Disord 1995;18:181-7.

Anckarsäter, H., Hofvander, B., Billstedt, E., Gillberg, I. C., Gillberg, C., Wentz, E., \& Rå stam, M. (2012). The sociocommunicative deficit subgroup in anorexia nervosa: autism spectrum disorders and neurocognition in a community-based, longitudinal study. Psychological Medicine, 42, 1957-1967.

Anderson, D. W., Kish, L., Cornell, R. G. (1980). On Stratification, Grouping and Matching. Scandinavian Journal of Statistics, 7 (2): 61-66.

Bodell, L. P., Keel, P., K. (2010). Current treatment for anorexia nervosa: efficacy, safety, and adherence. Psychol Res Behav Manag, 3, 91-108.

Boyd, J. N., \& Zimbardo, P. G. (2005). Time perspective, health and risk taking. In A. Strathman, \& J. Joireman (Eds.), Understanding behavior in the context of time: Theory, research, and applications in social personality, health and environmental psychology (pp. 85-107). Mahwah, NJ: Erlbaum. 
428 Brand-Gothelf A, Leor S, Apter A, Fennig S (2014) The impact of comorbid and depressive and

429

430

431

432

433

434

435

436

437

438

439

440

441

442

443

444

445

446

447

448

449

anxiety disorders on severity of anorexia nervosa in adolescent girls. J Nerv Ment Dis 202, 759-762.

Bruehlman-Senecal E, Ayduk O (2015) This too shall pass: temporal distance and the regulation of emotional distress. J Pers Soc Psychol. 108(2):356-75. doi: 10.1037/a0038324.

Butler, A. C., Chapman, J. E., Forman, E., \& Beck, A. T. (2006). The empirical status of cognitive-behavioral therapy: A review of meta-analyses. Clinical Psychology review, 26, 17-31. DOI: 10.1016/j.cpr.2005.07.003.

Cardi V, Esposito M, Bird G, Rhind C, Yiend J, Schifano S, Hirsch C, Treasure J (2015). A preliminary investigation of a novel training to target cognitive biases towards negative social stimuli in Anorexia Nervosa. J Affect Disord. 2015 Dec 1;188:188-93. doi: 10.1016/j.jad.2015.08.019.

Cassin, S. E., \& von Ranson, K. M. (2005). Personality and Eating Disorders: A Decade in Review. Clinical Psychology Review, 25, 895-916. DOI :10.1016/j.cpr.2005.04.012.

Cloninger, R. C. (2004). Feeling Good: The Science of Well-Being. New York, NY: Oxford University Press.

Cloninger, C. R. (2006). The Science of Well-Being: An integrated approach to mental health and its disorders. World Psychiatry, 5, 71-76.

Cloninger, C. R. (2007). Spirituality and the science of feeling good. Southern Medical Journal, $100,740-743$.

Cloninger, C. R. (2013). What makes people healthy, happy, and fulfilled in the face of current world challenges? Mens Sana Monographs, 11, 16-24. DOI: 10.4103/0973-1229.109288. 
450 Cloninger, C. R., \& Garcia, D. (2015). The Heritability and Development of Positive Affect and 451 Emotionality. In M. Pluess (Ed.), Genetics of Psychological Well-Being - The Role of

452

453

454

455

456

457

458

459

460

461

462

463

464

465

466

467

468

469

470

471 Heritability and Genetics in Positive Psychology (pp. 97-113). New York: Oxford University Press.

Culbert KM, Lavender JM, Crosby RD, Wonderlich SA, Engel SG, Peterson CB, Mitchell JE, Crow SJ, Le Grange D, Cao L, Fischer S (2016) Associations between negative affect and binge/purge behaviors in women with anorexia nervosa: Considering the role of negative urgency. Compr Psychiatry. 66:104-12. doi: 10.1016/j.comppsych.2016.01.010.

Dapelo MM, Bodas S, Morris R, Tchanturia K (2016) Deliberately generated and imitated facial expressions of emotions in people with eating disorders. J Affect Disord. 191:1-7. doi: 10.1016/j.jad.2015.10.044.

Díaz-Morales, J. F. (2006). Estructura factorial y fiabilidad del Inventario de Perspective Temporal de Zimbardo. Psicothema, 18, 565-567.

Díaz-Morales JF, Ferrari JR, Cohen JR. 2008. Indecision and avoidant procrastination: the role of morningness-eveningness and time perspective in chronic delay lifestyles. Journal of General Psychology 135:228-240 DOI 10.3200/GENP.135.3.228-240.

Fava, G. A., \& Ruini, C. (2003). Development and characteristics of a well-being enhancing psychotherapeutic strategy: well-being therapy. Journal of Behavior Therapy and Experimental Psychiatry, 34, 45-63.

Fava, G. A., Rafanelli, C., Cazzarro, M., Conti, S., \& Grandi, S. (1998). Well-being therapy. A novel psychotherapeutic approach for residual symptoms of affective disorders. Psychological Medicine, 28, 475-480. 
472 Fava, G. A., Ruini, C., Rafanelli, C., Finos, G. A., Salmaso, L., Mangelli, L., \& Sirigatti, S. 473 (2005). Well- being therapy of generalized anxiety disorder. Psychother Psychosom, 74, 474 26-30.

475

476

477

478

479

480

481

482

483

484

485

486

487

488

489

490

491

492

493

494

Fava, A. G., \& Tomba, E. (2009). Increasing Psychological Well-Being and Resilience by Psychotherapeutic Methods. Journal of Personality, 77, 1903-1934.

Garcia, D. (2011a). Two Models of Personality and Well-Being among Adolescents. Personality and Individual Differences, 50, 1208-1212. DOI: 10.1016/j.paid.2011.02.009.

Garcia, D. (2011b). Happy Today, Happy Tomorrow: The (Non-)Effect of Temporal Distance on Life Satisfaction. Personality and Individual Differences, 51, 1048-1051. DOI: 10.1016/j.paid.2011.07.031.

Garcia, D. (2012). The Affective Temperaments: Differences between Adolescents in the Big Five Model and Cloninger's Psychobiological Model of Personality. Journal of Happiness Studies, 13, 999-1017. DOI: 10.1007/s10902-011-9303

Garcia, D., Cloninger, K. M., Lester, N., \& Cloninger, C. R. (2017). Self-directedness. In V. Zeigler-Hill \& T. Shackelford (Eds.), Encyclopedia of Personality and Individual Differences. Springer. DOI: 10.1007/978-3-319-28099-8_1163-1.

Garcia, D., Drugge, A., Blixt Samuelsson, H., Storm, U., Archer, T., \& Cloninger, K. M. (2016). The Need of Holistic Interventions in Schools: The Promotion of Healthy and Sustainable Personality Development among Children. Clinical and Experimental Psychology, 2:2. DOI: $10.4172 / 2471-2701.1000129$.

Garcia, D., Ghiabi, B., Moradi, S., Siddiqui, A., \& Archer, T. (2013). The Happy Personality: A Tale of Two Philosophies. In E. F. Morris \& M-A. Jackson (Eds.), Psychology of Personality (pp. 41-59). New York: Nova Science Publishers. 
495 Garcia, D., Lester, N., Cloninger, K. M., \& Cloninger, C. R. (2017a). Cooperativeness. In V. 496 Zeigler-Hill \& T. Shackelford (Eds.), Encyclopedia of Personality and Individual Differences. Springer. DOI: 10.1007/978-3-319-28099-8_2268-1.

498 Garcia, D., Lester, N., Cloninger, K. M., \& Cloninger, C. R., (2017b). The Temperament and 499 Character Inventory (TCI). In V. Zeigler-Hill \& T. Shackelford (Eds.), Encyclopedia of $500 \quad$ Personality and Individual Differences (pp. 1-3). Springer. DOI: 10.1007/978-3-319501 28099-8_91-1.

502 Garcia, D., Nima, A. A., \& Lindskär, E. (2016). Time Perspective and Well-Being: Swedish 503 Survey Questionnaires and Data. Data in Brief, 9, 183-193. DOI: 10.1016/j.dib.2016.08.057.

505

506

507

508

509

510

511

512

513

514 515

516 517

Garcia, D., \& Rosenberg, P. (2016). Out of Flatland: The Role of the Notion of a Worldview in the Science of Well-Being. Men Sana Monographs, 14, 133-140. DOI: 10.4103/09731229.193082.

Garcia D, Rosenberg P, Siddiqui A. 2011. Tomorrow I could be in trouble...but the Sun will come out next year: the effect of temporal distance on adolescents' judgments of life satisfaction. Journal of Adolescence 34:751-757. DOI 10.1016/j.adolescence.2010.08.006.

Garcia D, Sailer U, Nima AA, Archer T (2016) Questions of time and affect: a person's affectivity profile, time perspective, and well-being. PeerJ. 4:e1826. doi: $10.7717 /$ peerj. 1826.

Gosling, S. D., Rentfrow, P. J., \& Swann, W. B. Jr., (2003). A very brief measure of the Big Five personality domains. Journal of Research in Personality, 37, 504-528.

Harney MB, Fitzsimmons-Kraft EE, Maldonado CR, Bardone-Cone AM (2014) Negative affective experiences in relation to stages of eating disorder recovery. Eat Behav 15, 24-30. 
518 Harrison, A., Fisher, M., Watling, R., \& Sternheim, L. (2016). Understanding Intolerance of 519 Uncertainty in Women with Eating Disorder Symptoms: Personality Traits and Attachment Styles. Eating Disorders International Conference in London, 17 $7^{\text {th }}$ March 2016.

521 Hofmann, S. G., Asnaani, A., Vonk, I. J. J., Sawyer, A. T., \& Fang, A. (2012). The Efficacy of Cognitive Behavioral Therapy: A Review of Meta-analyses. Cognitive Therapy and Research, 36(5), 427-440. DOI: 10.1007/s10608-012-9476-1.

524

525

526

527

528

529

530

531

532

533

534

535

536

537

538

539

Huppert, F. A., \& Whittington, J. E. (2008). Evidence for the independence of positive and negative well- being: implications for quality of life assessment. British Journal of Health Psychology, 8, 107-122.

Keough, K. A., Zimbardo, P. G., \& Boyd, J. N. (1999). Who’s Smoking, Drinking and Using Drugs? Time Perspective as a Predictor of Substance Abuse. Basic and Applied Social Psychology, 21, 149-164.

Kitsantas, A., Gilligan, T., \& Kamata, A. (2003). College Women With Eating Disorders: SelfRegulation, Life Satisfaction, and Positive/ Negative Affect. Journal of Psychology, 137, 381-395. doi:10. 1080/00223980309600622.

Laghi, F., Liga, F., Baumgartner, E., \& Baiocco, R. (2012). Time perspective and psychosocial positive functioning among Italian adolescents who binge eat and drink. Journal of Adolescence, 35, 1277-1284. DOI:10.1016/j.adolescence.2012.04.014

Lavender JM, Mason TB, Utzinger LM, Wonderlich SA, Crosby RD, Engel SG, Mitchell JE, Le Grange D, Crow SJ, Peterson CB (2016) Examining affect and perfectionism in relation to eating disorder symptoms among women with anorexia nervosa. Psychiatry Res. 241:267272. doi: 10.1016/j.psychres.2016.04.122. 
540 Lee, S. J., Cloninger, C. R., \& Chaea, H. (2015). Cloninger's temperament and character traits in 541 medical students of Korea with problem eating behaviors. Comprehensive Psychiatry, 59, 98-106. DOI: 10.1016/j.comppsych.2015.02.006.

543 Lilenfeld LR, Wonderlich S, Riso LP, Crosby R, Mitchell J. Eating disorders and personality: a 544 methodological and empirical review. Clin Psychol Rev. 2006;26(3):299-320.

Liniauskaite, A., \& Kairys, A. (2009). The Lithuanian version of the Zimbardo Time Perspective Inventory (ZTPI) Psichologija, 2009, 40, 66-87.

547

548

549

550

551

552

553

554

555

556

557

558

559

560

561

Lundblad S, Hansson B, Archer T (2014) Affect-group intervention for alexithymia in eating disorders. Int J Emerg Ment Heal Hum Resourc 17, 219-223.

Lundblad S, Garcia D, Hansson B, Archer T (2015) Emotional well-being in anorexia nervosa: negative affect, sleeping problems, use of mood-enhancing drugs and exercise frequency. Arch Depress Anxiety 1, 001-005.

Lundblad S, Magnusson J, Hansson B, Archer T (2015) Cognitive-affective status in anorexia nervosa: self-image and absence of positive emotions. Clin Exp Psychol 1:1, DOI: 10.4172/cep.1000004.

Milfont TL, Wilson J, Diniz P. 2012. Time perspective and environmental engagement: a metaanalysis. International Journal of Psychology 47:325-334 DOI $10.1080 / 00207594.2011 .647029$.

Moore, T., Kapur, N., Hawton, K., Richards, A., Metcalfe, C., \& Gunell, D. G. (2016). OP13 Interventions to ameliorate the impact of unemployment and economic hardship on mental health in the general population: Systematic review. J Epidemiol Community Health, 70, A12-A13. 
562 Pavot W, Diener E, Suh E. 1998. The temporal satisfaction with life scale. Journal of Personality 563 Assessment 2:340-354 DOI 10.1207/s15327752jpa7002_11.

564 Phillipou A, Abel LA, Castle DJ, Hughes ME, Gurvich C, Nibbs RG, Rossell SL (2015) Self565 perception and facial emotion perception of others in anorexia nervosa. Front Psychol. 6:1181. doi: 10.3389/fpsyg.2015.01181.

Rubin, D. B. (1973). Matching to Remove Bias in Observational Studies. Biometrics. 29 (1): 159-183. DOI: $10.2307 / 2529684$.

Ruini, C. (2017). Positive Personality Traits and Positive Human Functioning. In C. Ruini, 570 Positive Psychology in the Clinical Domain. Springer.

Ruini, C., Albieri, E., \& Vescovelli, F. (2014). Well-Being Therapy: State of the Art and Clinical Exemplifications. Journal of Contemporary Psychotherapy, 45, 129-136. DOI: 10.1007/s10879-014-9290-z.

Ruini, C., Belaise, C., Brombin, C., Caffo, E., Fava, G. A. (2006). Well-Being Therapy in School Settings: A Pilot Study. Psychotherapy and Psychosomatics, 75:331-336. DOI: $10.1159 / 000095438$.

Ruini, C., Masoni, L., Ottolini, F., \& Ferrari, S. (2014). Positive Narrative Group Psychotherapy: the use of traditional fairy tales to enhance psychological well-being and growth. sychology of Well-Being: Theory, Research and Practice, 4:13.

Ruini, C., Vescovelli, F., Carpi, V., Masoni, L. (2017). Exploring Psychological Well-Being and Positive Emotions in School Children Using a Narrative Approach. Indo-Pacific Journal of Phenomenology, 17, 1-9. DOI: 10.1080/20797222.2017.1299287. 
583 Sailer U, Rosenberg P, Nima AA, Gamble A, Gärling T, Archer T, Garcia D. (2014). A happier 584 and less sinister past, a more hedonistic and less fatalistic present and a more structured future: time perspective and well-being. PeerJ 2:e303. DOI 10.7717/peerj.303.

586

587

588

589

590

591

592

593

594

595

596

597

598

599

600

601

602

603

Seidel M, Petermann J, Diestel S, Ritschel F, Boehm I, King JA, Geisler D, Bernardoni F, Roessner V, Goschke T, Ehrlich S (2016) A naturalistic examination of negative affect and disorder-related rumination in anorexia nervosa. Eur Child Adolesc Psychiatry. 2016 Mar 31.

Spring JL, Bulik CM (2014) Implicit and explicit affect towards food and weight stimuli in anorexia nervosa. Eat Behav 15, 91-94.

Sternheim L, Konstantellou A, Startup H, Schmidt U. (2011). What does uncertainty mean to women with anorexia nervosa? An interpretative phenomenological analysis. Eur Eat Disord Rev. 19(1),12-24.

Sternheim, L., Startup, H., \& Schmidt, U. (2011). An experimental exploration of behavioral and cognitive-emotional aspects of intolerance of uncertainty in eating disorder patients. Journal of Anxiety Disorders, 25, 806-812.

Sternheim L, Startup H, Schmidt U. (2015). Anxiety-related processes in anorexia nervosa and their relation to eating disorder pathology, depression and anxiety. Advanc in Eat Disord: Theory, Research and Practice, 3(1).

Stolarski M, Matthews G, Postek S, Zimbardo PG, Bitner J. 2013. How we feel is a matter of time: relationships between time perspective and mood. Journal of Happiness Studies DOI 10.1007/s10902-013-9450-y. 
604 Tenconi E, Degortes D, Clementi M, Collantoni E, Pinato C, Forzan M, Cassina M, Santonastaso

605 P, Favaro A (2016) Clinical and genetic correlates of decision making in anorexia nervosa. $606 \quad$ J Clin Exp Neuropsychol. 38(3):327-37. doi: 10.1080/13803395.2015.1112878.

607 Tomba E, Offidani E, Tecuta L, Schumann R, Ballardini D (2014) Psychological well-being in 608 out-patients with eating disorders: a controlled study. Int J Eat Dis 47, 252-258.

609 Wang, P. S., Simon, G. E., Avorn, J., Azocar, F., Ludman, E. J., McCulloch, J., Petukhova, M. 610 Z., \& Kessler, R. C. (2007). Telephone screening, outreach, and care management for 611 depressed workers and impact on clinical and work productivity outcomes: a randomized 612 controlled trial. Journal of the American Medical Association, 298, 1401-1411

613 Zhang, J. W., \& Howell, R. T. (2011). Do time perspectives predict unique variance in life 614 satisfaction beyond personality traits? Personality and Individual Differences, 50, 1261$615 \quad 1266$.

616 Zimbardo PG, Boyd JN (1999) Putting time in perspective. A valid, reliable individual 617 differences metric. J Pers Soc Psychol 77, 1271-1288.

618 Zimbardo PG, Keough KA, Boyd JN (1997) Present time perspective as predictor of risky 619 driving. Pers Individ Dif 23, 1007-1023. 


\section{Table 1 (on next page)}

Means, standard deviations ( $\mathrm{Sd}$.), and results of the t-tests 
1 Table 1. Means, standard deviations (Sd.), and results of the t-tests comparing the five time perspective dimensions, the Big Five

2 personality traits, and temporal satisfaction with life between anorexia nervosa patients and controls.
Anorexia Patients
Controls
t-tests' results

\begin{tabular}{|c|c|c|c|c|c|c|c|}
\hline & Mean & $S d$. & Mean & $S d$. & $t$ & $d f$ & $p$ \\
\hline Past Negative & 3.50 & 0.75 & 2.98 & 0.80 & 4.59 & 192 & $<.001$ \\
\hline Past Positive & 2.78 & 0.73 & 3.44 & 0.70 & -6.46 & 195 & $<.001$ \\
\hline Present Fatalistic & 2.51 & 0.55 & 2.28 & 0.61 & 2.68 & 192 & $<.01$ \\
\hline Present Hedonistic & 2.65 & 0.65 & 3.18 & 0.55 & -6.15 & 194 & $<.001$ \\
\hline Future & 3.58 & 0.52 & 3.33 & 0.57 & 3.06 & 192 & $<.01$ \\
\hline Openness to Experience & 4.79 & 1.46 & 4.28 & 2.45 & 1.68 & 192 & .096 \\
\hline Conscientiousness & 4.98 & 1.53 & 3.67 & 2.36 & 4.44 & 191 & $<.001$ \\
\hline Extraversion & 4.74 & 1.52 & 3.73 & 2.47 & 3.32 & 192 & $<.01$ \\
\hline Agreeableness & 5.11 & 1.13 & 4.01 & 2.48 & 3.77 & 191 & $<.001$ \\
\hline Emotional Stability & 3.16 & 1.46 & 3.71 & 2.42 & -1.85 & 193 & .066 \\
\hline Temporal Satisfaction with Life & 2.82 & 1.03 & 4.10 & 1.16 & -8.06 & 194 & $<.001$ \\
\hline
\end{tabular}

3 Note: Pink cells mark variables in which anorexia nervosa patients scored significantly higher compared to controls; Blue cells mark

4 variables in which controls scored significantly higher compared to anorexia nervosa patients. 


\section{Table 2 (on next page)}

Results of the hierarchical multiple regression analyses, for each group 
1 Table 2. Results of the hierarchical multiple regression analyses, for each group, in which 2 temporal satisfaction with life was the outcome, the Big Five personality traits the predictors in 3 the first step, and the five time perspective dimensions the predictors in the second step of the 4 regression.

\begin{tabular}{|c|c|c|c|c|c|c|c|}
\hline Group & Variable & $\beta$ & $t$ & $R$ & $R^{2}$ & $\Delta R^{2}$ & $p$ \\
\hline \multirow{17}{*}{ 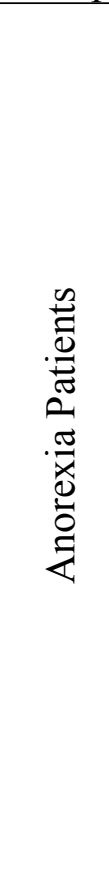 } & STEP 1 & & & .48 & .23 & .23 & \\
\hline & Openness to Experience & 0.02 & 0.15 & & & & .882 \\
\hline & Conscientiousness & 0.18 & 1.48 & & & & .145 \\
\hline & Extraversion & 0.22 & 1.70 & & & & .093 \\
\hline & Agreeableness & -0.13 & -1.04 & & & & .302 \\
\hline & Emotional Stability & 0.33 & 2.66 & & & & $<.05$ \\
\hline & STEP 2 & & & .67 & .45 & .23 & \\
\hline & Openness to Experience & -0.10 & -0.92 & & & & .363 \\
\hline & Conscientiousness & 0.25 & 1.83 & & & & .073 \\
\hline & Extraversion & 0.04 & 0.30 & & & & .764 \\
\hline & Agreeableness & -0.01 & -0.08 & & & & .934 \\
\hline & Emotional Stability & 0.08 & 0.62 & & & & .539 \\
\hline & Past Negative & -0.22 & -1.86 & & & & .068 \\
\hline & Past Positive & 0.24 & 2.33 & & & & $<.01$ \\
\hline & Present Fatalistic & -0.17 & -1.42 & & & & .161 \\
\hline & Present Hedonistic & 0.50 & 3.47 & & & & $<.001$ \\
\hline & Future & 0.16 & 1.14 & & & & .259 \\
\hline
\end{tabular}

\begin{tabular}{lcccccc} 
STEP 1 & & & .46 & .21 & .21 & \\
Openness to Experience & $\mathbf{- 0 . 8 7}$ & $\mathbf{- 3 . 4 7}$ & & & & $<.001$ \\
Conscientiousness & 0.05 & 0.24 & & & & .814 \\
Extraversion & 0.36 & 1.82 & & & & .071 \\
Agreeableness & -0.05 & -0.17 & & & & .866 \\
Emotional Stability & $\mathbf{0 . 7 6}$ & $\mathbf{3 . 9 6}$ & & & & $<.001$ \\
& & & & & & \\
STEP 2 & & & .82 & .67 & .46 & \\
Openness to Experience & -0.06 & -0.32 & & & & .746 \\
Conscientiousness & -0.14 & -0.83 & & & & .409 \\
Extraversion & -0.05 & -0.35 & & & & .729 \\
Agreeableness & -0.07 & -0.36 & & & .721 \\
Emotional Stability & $\mathbf{0 . 3 2}$ & $\mathbf{2 . 2 7}$ & & & & $<.05$ \\
Past Negative & $\mathbf{- 0 . 5 9}$ & $-\mathbf{7 . 8 6}$ & & & & $<.001$ \\
Past Positive & $\mathbf{0 . 2 6}$ & $\mathbf{3 . 7 9}$ & & & & $<.001$ \\
Present Fatalistic & -0.13 & -1.94 & & & .056 \\
Present Hedonistic & 0.06 & 0.85 & & & .397 \\
Future & 0.10 & 1.36 & & & .178 \\
\hline
\end{tabular}

5 Note: Significant results in bold type. Pink marks results for anorexia nervosa patients and blue

6 cells mark results for controls. 